\title{
Editorial
}

\section{Pharmacometrics: a quantitative tool of pharmacological research}

\author{
Qing-shan ZHENG* ${ }^{*}$ Lu-jin LI \\ Center for Drug Clinical Research, Shanghai University of Chinese Medicine, Shanghai 201203, China
}

Acta Pharmacologica Sinica (2012) 33: 1337-1338; doi: 10.1038/aps.2012.149

Pharmacometrics is an interdisciplinary science with tremendous potential to influence decision making through the construction of mathematical and statistical models combined with graphical methods that define, challenge, and resolve queries surrounding the biological processes of a drug. In 2004, FDA published the white paper the Challenge and Opportunity on the Critical Path to New Products, which advocates the model-based drug development (MBDD). Since then, pharmacometric analysis has become an increasingly important component of New Drug Application (NDA) and Biological License Application (BLA) submitted to FDA for drug approval, labeling and trial design decisions ${ }^{[1,2]}$. The academic clinical researchers are likewise confronted with the need to use data from various sources (experimental biology, preclinical models of disease, etc) in order to organize translational clinical studies in a therapeutic area. The administrators are faced with bringing together a variety of data (preclinical and clinical data, literatures, and other regulatory submissions of similar therapies) in order to make regulatory decisions. A great deal has been published in the literatures on quantitative research, especially in the field of clinical pharmacology. Therefore, wherever in industry, academia, or regulatory agencies, pharmacometrics is at the center of the translational medicine paradigm ${ }^{[3,4]}$. It is difficult to imagine a more efficient, powerful, and informative drug development and evaluation process without comprehensive pharmacometric studies.

China is growing to be not only one of the biggest pharmaceutical markets in the world, but potentially one of most productive countries in R\&D of new drugs as well. since 1979, the Professional Committee of Mathematical Pharmacology (PCMP) led by the Chinese Society of Pharmacology has been devoting to promote research, education and training of Chinese scientists in academia, industry and regulatory agencies with regard to the use of PK/PD modeling to help drug development and to

\footnotetext{
* To whom correspondence should be addressed.

E-mail qingshan.zheng@drugchina.net
}

optimize drug application in clinical therapies ${ }^{[5,6]}$. The papers organized by PCMP in this Special Issue of Acta Pharmacologica Sinica are focused on phase I trial design ${ }^{[7]}$, phase I PK study $^{[8,9]}$, physiologically based PK modelling $(\mathrm{PBPK})^{[10]}$, PK/ PD linking ${ }^{[11-14]}$, population approach ${ }^{[15-17]}$, dose finding ${ }^{[18]}$, and stochastic simulation ${ }^{[19]}$. We hope that these papers serve as an introduction for the readers in academia, regulatory authorities and pharmaceutical industry to understand the role of pharmacometrics in drug development and approval processes, which will improve the success rate in drug development, and the beneficiaries will ultimately be the patients in need.

\section{References}

1 Kola I, Landis J. Can the pharmaceutical industry reduce attrition rates? Nat Rev Drug Discov 2004; 3: 711-5.

2 US department of health and human aervices, food and drug administration. Innovation or stagnation? Challenge and opportunity on the critical path to new medical products, http://www.fda.gov/oc/ initiatives/criticalpath/whitepaper.pdf. 2004.

3 Ette El, Williams PJ. Pharmacometrics: The science of quantitative pharmacology. John Wiley \& Sons: Hoboken 2007: 1-21.

4 Lalonde RL, Kowalski KG, Hutmacher MM, Ewy W, Nichols DJ, Milligan PA, et al. Model-based drug development. Clin Pharmacol Ther 2007; 82: 21-32.

5 Sun RY. Quantitative pharmacology. The People Health Publisher 1987: 1-9.

6 Sun RY, Zheng QS. New Theory of Mathematical Pharmacology. The People Health Publisher 2004: 1-20.

7 Zhao L, Ren TH, Wang DD. Clinical pharmacology considerations in biologics development. Acta Pharmacol Sin 2012; 33: 1339-47.

8 Zhao LS, Yin R, Wei BB, Li Q, Jiang ZY, Chen XH, et al. Comparative pharmacokinetics of cefuroxime lysine after single intravenous, intraperitoneal, and intramuscular administration to rats. Acta Pharmacol Sin 2012; 33: 1348-52.

9 Feng S, Jiang J, Hu P, Zhang JY, Liu T, Zhao Q, et al. A phase I study on pharmacokinetics and pharmacodynamics of higenamine in healthy Chinese subjects. Acta Pharmacol Sin 2012; 33: 1353-8.

10 Li GF, Wang K, Chen R, Zhao HR, Yang J, Zheng QS. Simulation of 
the pharmacokinetics of bisoprolol in healthy adults and patients with impaired renal function using whole-body physiologically based pharmacokinetic modeling. Acta Pharmacol Sin 2012; 33: 1359-71.

11 Zhang J, Li P, Guo HF, Liu L, Liu XD. Pharmacokinetic-pharmacodynamic modeling of diclofenac in normal and Freund's complete adjuvant-induced arthritic rats. Acta Pharmacol Sin 2012; 33 : 1372-8.

12 Li XG, Li L, Zhou X, Chen Y, Ren YP, Zhou TY, et al. Pharmacokinetic/ pharmacodynamic studies on exenatide in diabetic rats. Acta Pharmacol Sin 2012; 33: 1379-86.

13 Zhang DM, Wang K, Zhao X, Li YF, Zheng QS, Wang ZN, et al. Population pharmacokinetics and pharmacodynamics of bivalirudin in young healthy Chinese volunteers. Acta Pharmacol Sin 2012; 33: 1387-94.

14 Cui YM, Wang ZN, Chen XW, Zhang HL, Zhao X, Zhou Y. Pharmacokinetics and pharmacodynamics of single and multiple doses of prasugrel in healthy native Chinese subjects. Acta Pharmacol Sin 2012; 33: 1395-400.

15 Wu KH, Guo T, Deng CH, Guan Z, Li L, Zhou TY, et al. Population pharmacokinetics of modafinil acid and estimation of the metabolic conversion of modafinil into modafinil acid in 5 major ethnic groups of China. Acta Pharmacol Sin 2012; 33: 1401-8.

16 Li L, Shang DW, Li WB, Guo W, Wang XP, Ren YP, et al. Population pharmacokinetics of clozapine and its primary metabolite norclozapine in Chinese patients with schizophrenia. Acta Pharmacol Sin 2012; 33: 1409-16.

17 He DK, Wang L, Lu W, Qin J, Zhang S, Li L, et al. Population pharmacokinetics of lamotrigine in Chinese children with epilepsy. Acta Pharmacol Sin 2012; 33: 1417-23.

18 Li YF, Wang K, Yin F, He YC, Huang JH, Zheng QS. Dose findings of antofloxacin hydrochloride for treating bacterial infections in an early clinical trial using PK-PD parameters in healthy volunteers. Acta Pharmacol Sin 2012; 33: 1424-30.

19 Ding JJ, Zhang YJ, Jiao Z, Wang Y. The effect of poor compliance on the pharmacokinetics of carbamazepine and its epoxide metabolite using Monte Carlo simulation. Acta Pharmacol Sin 2012; 33: 143140. 